\title{
Extraction optimization of polyphenols, antioxidant and xanthine oxidase inhibitory activities from Prunus salicina Lindl.
}

\author{
Yibin $\mathrm{LI}^{1}$, Pufu LAI ${ }^{1}$, Junchen $\mathrm{CHEN}^{1 *}$, Hengsheng $\mathrm{SHEN}^{1}$, Baosha TANG ${ }^{1}$, Li WU ${ }^{1}$, Minjie WENG ${ }^{1}$
}

\begin{abstract}
Optimization of polyphenols extraction from plum (Prunus salicina Lindl.) was evaluated using response surface methodology. The Box-Behnken experimental results showed the optimal conditions involved an extraction temperature of $59^{\circ} \mathrm{C}$, a sonication time of $47 \mathrm{~min}$, and an ethanol concentration of $61 \%$ respectively. The maximum extraction yield of total polyphenols was $44.74 \mathrm{mg}$ gallic acid equivalents per gram of dried plum at optimal conditions. Polyphenol extracts exhibited stronger antioxidant activities than $\mathrm{V}_{c}$ by evaluating of 1,1-diphenyl-2-picrylhydrazyl (DPPH) and hydroxyl radical scavenging activity. Furthermore, polyphenol extracts $\left(\mathrm{IC}_{50}=179 \mathrm{~g} / \mathrm{mL}\right)$ showed obvious inhibitory effects on xanthine oxidase. These findings suggest that polyphenol extracts from $P$. salicina can be potentially used as natural antioxidant and xanthine oxidase inhibitory agents.
\end{abstract}

Keywords: Prunus salicina Lindl.; polyphenols; response surface methodology; antioxidant activities; xanthine oxidase inhibitory.

Practical Application: P. salicina polyphenols can be potentially used as natural antioxidant and xanthine oxidase inhibitor.

\section{Introduction}

Polyphenolic compounds are a group of biologically active molecules and one of the most important classes of secondary plant metabolites. Plant polyphenols play important roles in the prevention of chronic diseases, such as cardiovascular diseases, neurodegenerative disorders, cancer, type II diabetes and osteoporosis (Scalbert et al., 2005). Therefore, plant polyphenols have become one of hot spots in recent years, and they have been widely applied in the manufacturing of various functional products, such as colorant or a functional ingredient, and in the nutraceutical and pharmaceutical industries (VallverdúQueralt et al., 2015; Pérez-Jiménez et al., 2010).

Plum (Prunus salicina Lindl.) is an important stone fruit which is widely planted in China, Japan, Europe, South African, Chile and the United States (Food and Agricultural Organization of the United Nations, 2016). China produced approximately 6022744 tons of plums during 2012, which was the country producing the largest yields of plums per annum (Food and Agricultural Organization of the United Nations, 2016). In addition, Fu et al. (2011) reported that plums have a fairly high phenolic content in comparison to some other fruits such as apple, orange, grapes, banana and kiwifruit. However, there are no reports yet about optimization of polyphenols extraction and xanthine oxidase inhibitory from Prunus salicina Lindl.. Therefore, the present study was undertaken to optimize the extraction of polyphenols from Prunus salicina Lindl. by using response surface methodology (RSM), and subsequently evaluate the antioxidant and xanthine oxidase inhibitory activity. The results provided scientific reference for development of antioxidant products and xanthine oxidase inhibitors from Prunus salicina Lindl..

\section{Materials and methods}

\subsection{Plant materials and chemicals}

The plums of Prunus salicina Lindl. cv.Yanzhi were collected from Yongtai County, Fujian Province, China. After harvesting and cleaning, the plum was dried with hot air at $50^{\circ} \mathrm{C}$ and then stored at $-20^{\circ} \mathrm{C}$ refrigerator in the dark. Before extraction, dried plums were milled and sieved (particle size range from 0.5 to $2.0 \mathrm{~mm}$ ). Gallic acid and 1,1-diphenyl-2-picrylhydrazyl (DPPH) were purchased from Shanghai Yuanye Biotechnology Co., Ltd.. All other organic solvents used in the study were analytical grade.

\subsection{Polyphenols extraction}

Five grams of samples were placed in a capped triangular flask $(250 \mathrm{~mL})$ and mixed with ethanol. The extraction process was conducted in an ultrasonic bath (KQ-600DV, $40 \mathrm{kHz}$, 300W, Kunshan Ultrasonic Instrument Co. Jiangsu, China). After ultrasonic extraction, the mixture was filtered (Whatman No.1 paper). Then the filtrate was collected in volumetric flask and used for the determination of the total polyphenol content. The filtrate was evaporated by a rotary evaporator (at $0.09 \mathrm{MPa}$, $45^{\circ} \mathrm{C}$ ) and then the extracts were lyophilized. The plum extracts were stored at $-20^{\circ} \mathrm{C}$ for further use. Samples were re-suspended in distilled water for determination of antioxidant and xanthine oxidase inhibitory activities. 


\subsection{Experimental design}

On the basis of single factors experiment, RSM was applied to evaluate the influence of three independent variables on extraction of polyphenols. The main factors affecting extraction efficiency, including the extraction temperature $\left({ }^{\circ} \mathrm{C}, \mathrm{X}_{1}\right)$, sonication time $\left(\min , \mathrm{X}_{2}\right)$ and ethanol concentration $\left(\%, \mathrm{X}_{3}\right)$ were selected as independent variables. The coded values of the experimental factors and their levels for the Box-Behnken Design were presented in Table 1 . The complete design was carried out in random order and consisted of 17 combinations including five replicates at central point (Table 2). Statistical analysis was performed using the Design-Expert.V8.0.6.1 software (State-Ease lnc., Minneapolis, MN, USA). Experimental data were fitted to a second-order polynomial model where multiple regression analysis and analysis of variance were used to determine fitness of the model and optimal conditions for investigated responses. All of the treatments were performed in triplicate.

\subsection{Determination of total polyphenol content}

Total polyphenol content in the extracts was determined with colorimetry by using the Folin-Ciocalteu method (Wood et al., 2002). Briefly, $2.5 \mathrm{~mL}$ diluted Folin-Ciocalteu reagent (10\%, v/v) was mixed with $200 \mu \mathrm{L}$ of sample. After 2 min of incubation in the dark at room temperature, $2 \mathrm{~mL}$ of aqueous sodium carbonate $(7.5 \%, \mathrm{w} / \mathrm{v})$ was added to the mixture. And then it was made up $10 \mathrm{~mL}$ by adding distilled water. After gentle vibration, the mixture

Table 1. Levels of variables for the experimental design.

\begin{tabular}{clccc}
\hline \multirow{2}{*}{ Symbols } & \multirow{2}{*}{ Independent variables } & \multicolumn{3}{c}{ Factor levels } \\
\cline { 3 - 5 } & & -1 & 0 & 1 \\
\hline $\mathrm{X}_{1}$ & Extraction temperature $\left({ }^{\circ} \mathrm{C}\right)$ & 40 & 50 & 60 \\
$\mathrm{X}_{2}$ & Sonication time $(\mathrm{min})$ & 30 & 45 & 60 \\
$\mathrm{X}_{3}$ & Ethanol concentration $(\%, \mathrm{v} / \mathrm{v})$ & 40 & 60 & 80 \\
\hline
\end{tabular}

Table 2. Box-Behnken design (uncoded) arrangement for extraction and the responses of polyphenols (mg GAE/g DP).

\begin{tabular}{ccccc}
\hline Run & $\mathrm{X}_{1}\left({ }^{\circ} \mathrm{C}\right)$ & $\mathrm{X}_{2}(\mathrm{~min})$ & $\mathrm{X}_{3}(\%)$ & $\mathrm{Y}(\mathrm{mg} \mathrm{GAE} / \mathrm{g} \mathrm{DP})^{*}$ \\
\hline 1 & 50 & 45 & 60 & $39.01 \pm 0.56$ \\
2 & 60 & 45 & 40 & $40.55 \pm 0.49$ \\
3 & 60 & 30 & 60 & $40.41 \pm 0.71$ \\
4 & 40 & 45 & 80 & $24.27 \pm 0.38$ \\
5 & 60 & 60 & 60 & $40.11 \pm 0.36$ \\
6 & 50 & 45 & 60 & $42.69 \pm 0.69$ \\
7 & 50 & 45 & 60 & $41.62 \pm 1.03$ \\
8 & 50 & 30 & 40 & $31.73 \pm 0.82$ \\
9 & 40 & 30 & 60 & $21.84 \pm 0.28$ \\
10 & 40 & 45 & 40 & $21.25 \pm 0.57$ \\
11 & 50 & 30 & 80 & $29.59 \pm 0.54$ \\
12 & 50 & 60 & 40 & $35.36 \pm 0.84$ \\
13 & 50 & 45 & 60 & $39.31 \pm 1.13$ \\
14 & 40 & 60 & 60 & $24.85 \pm 0.47$ \\
15 & 50 & 45 & 60 & $40.16 \pm 1.22$ \\
16 & 50 & 60 & 80 & $36.09 \pm 0.75$ \\
17 & 60 & 45 & 80 & $42.84 \pm 1.17$ \\
\hline
\end{tabular}

${ }^{\star}$ Mean values $(\mathrm{n}=3) \pm$ S.D. was placed in a water bath at $50{ }^{\circ} \mathrm{C}$ for $30 \mathrm{~min}$ and then rapidly cooled down to room temperature. Absorbance was measured at $765 \mathrm{~nm}$ using a UV-vis spectrophotometer (756P, Shanghai Spectrum Instruments Co., Ltd., China). Total polyphenol content was expressed as $\mathrm{mg}$ (gallic acid equivalent) per gram of dried plum (mg GAE/g DP).

\subsection{DPPH free radical scavenging capacity}

DPPH assay was done according to a method (Yu et al., 2005) with some modifications. $5 \mathrm{~mL}$ of $100 \mu \mathrm{M}$ DPPH dissolved in methanol was added to $1 \mathrm{~mL}$ of extract re-suspended in distilled water. After vigorously shaken, the mixtures were allowed to stand in the dark at $25^{\circ} \mathrm{C}$ for $30 \mathrm{~min}$. The absorbance was measured using a spectrophotometer at $517 \mathrm{~nm}$ against a blank sample without DPPH. The ability to scavenge the DPPH radical was calculated by using the Equation 1 below:

Antioxidant capacity $(\%$ inhibition $)=\left[\left(\mathrm{A}_{\mathrm{c}}-\mathrm{A}_{\mathrm{s}}\right) / \mathrm{A}_{\mathrm{c}}\right] \times 100$

where $\mathrm{A}_{c}$ is the absorbance of the control (DPPH solution without sample) and $A_{s}$ is the absorbance of the test sample.

\subsection{Hydroxyl radical scavenging capacity}

Hydroxyl radicals scavenging capacity was determined according to previously reported methods (Sun \& Kennedy, 2010) with some slight modifications. The test tube added $4.7 \mathrm{~mL}$ of ultrapure water, $1.0 \mathrm{~mL}$ of $0.15 \mathrm{M}$ phosphate buffer (pH 7.4), $2 \mathrm{~mL}$ of $0.52 \mathrm{mg} / \mathrm{mL}$ saffron solution, $1.0 \mathrm{~mL}$ of $6 \mathrm{mM}$ EDTA- $\mathrm{Na}_{2}-\mathrm{Fe}^{2+}$ and $0.5 \mathrm{~mL}$ of sample solution. The mixtures were shaken well and added $0.8 \mathrm{~mL}$ of $0.3 \% \mathrm{H}_{2} \mathrm{O}_{2}$, then immediately placed in $40^{\circ} \mathrm{C}$ water bath for $30 \mathrm{~min}$. The blank group was replaced by an equal volume of ultrapure water instead of the sample solution, and the control group was replaced by an equal volume of ultrapure water instead of the sample solution and $\mathrm{H}_{2} \mathrm{O}_{2}$ solution. Then absorbance was measured at $520 \mathrm{~nm}$ (756P spectrophotometer, Shanghai Spectrum Instruments Co., Ltd., China). The capability of scavenge hydroxyl radicals was calculated using the following Equation 2:

Hydroxyl radical scavenging ability $(\%)=\left[\left(\mathrm{A}_{\mathrm{s}}-\mathrm{A}_{\mathrm{b}}\right) /\left(\mathrm{A}_{\mathrm{c}}-\mathrm{A}_{\mathrm{b}}\right)\right] \times 100$

where $A_{b}, A_{c}$ and $A_{s}$ are the absorbance of the blank group, the control group and the test sample respectively.

\subsection{Xanthine oxidase inhibitory assay}

The assay was carried out based on a procedure reported by Orsolya et al. (2015) with slight modification. Briefly, test extracts were firstly dissolved in DMSO (1\%,v/v) and then and then the phosphate buffer solution $(0.2 \mathrm{M}, \mathrm{pH} 7.5)$ was used to prepare different concentrations. . The reaction mixture contained $50 \mu \mathrm{L}$ of test extract solution and $150 \mu \mathrm{L}$ of $0.4 \mathrm{mM}$ xanthine solution, and then the mixture was incubated for another $15 \mathrm{~min}$ at $25^{\circ} \mathrm{C}$. After adding $50 \mu \mathrm{L}$ of 0.05 units $/ \mathrm{mL}$ xanthine oxidase $(\mathrm{XO})$ solution, the mixture was incubated at room temperature $\left(25^{\circ} \mathrm{C}\right)$ for $30 \mathrm{~min}$. Finally $80 \mu \mathrm{L}$ of $1 \mathrm{M} \mathrm{HCl}$ was added to stop reaction. A blank solution was phosphate buffer 
(0.2 M, pH 7.5) instead of the test sample solution. Each mixture was measured uric acid production by high performance liquid chromatography (HPLC, LC-600 series, Nanjing Kejie Analysis Instrument Co. Ltd. China). The mixture was diluted 10 times with ultrapure water and was filtered through a $0.45 \mu \mathrm{m}$ nylon membranes (Millipore). The separation was performed with a mobile phase consisting of methanol and $0.015 \mathrm{M}$ dihydrogen phosphate amine solution $(15: 85, \mathrm{v} / \mathrm{v})$ and a chromatographic running time of $10 \mathrm{~min}$ at $25^{\circ} \mathrm{C}$ with a flow-rate of $0.8 \mathrm{~mL} / \mathrm{min}$, and chromatograms were monitored at $295 \mathrm{~nm}$. Allopurinol was used as a positive control. Three replicates were made for each test sample. The inhibition rate (\%) was calculated according to the following Equation 3:

Inhibition rate $(\%)=\left(1-\frac{A}{B}\right) \times 100$

where $\mathrm{A}$ is chromatographic peak area of uric acid in test sample; $\mathrm{B}$ is chromatographic peak area of uric acid in blank solution.

\section{Results and discussion}

\subsection{Fitting the response surface models}

Table 2 showed polyphenol compounds extracted from P. salicina ranged from $21.25 \pm 0.57$ to $42.84 \pm 1.17 \mathrm{mg} \mathrm{GAE} / \mathrm{g}$ DP. A second-order polynomial model describing the correlation between polyphenols yield and the three variables in this study was obtained in Equation 4 below:

$Y=-207.0203+6.0595 X_{1}+1.7974 X_{2}+1.0035 X_{3}-0.0055 X_{1} X_{2}-$

$0.0009 \mathrm{X}_{1} \mathrm{X}_{3}+0.0024 \mathrm{X}_{2} \mathrm{X}_{3}-0.0486 \mathrm{X}_{1}^{2}-0.0173 \mathrm{X}_{2}^{2}-0.0087 \mathrm{X}_{3}^{2}$

Significance and suitability of the design were then studied using an analysis of the variance (ANOVA, Table 3). According to Table 3, lack of fit $(p=0.2585>0.05)$ was not significant, which indicated that the regression equation fit well with the experimental results and the quadratic regression model was appropriate. Model $(p<0.0001)$ was significant, which indicated the suitability of regression equation to accurately predict the variation. $97.39 \%$ of the variability of responses was explained
$\left(R^{2}=0.9739\right)$, asserting a good accuracy and ability of the established model.

\subsection{Effect of extraction parameters on polyphenols}

Figure 1 presented the response surface and contour plots for the influences of extraction parameters on total polyphenol content. The temperature dominantly impacted response value in the processing of ultrasonic extraction by analyzing the slopes for each variable (Figure 1a and Figure 1b). The increased extraction yield of total polyphenols was observed with an increased temperature from $40^{\circ} \mathrm{C}$ to $59^{\circ} \mathrm{C}$. This may be due to multiple effects of temperature on mass-transfer process such as improved diffusivity, degradation of the plum matrix and improvement of solvent characteristics in terms of penetration and solubility of polyphenols (Ghitescu et al., 2015). The results are consistent with previous studies describing the extraction of polyphenols from spruce wood bark (Ghitescu et al., 2015) and Aronia melanocarpa by-product (Ramić et al., 2015). As shown in Figure 1c, it could be concluded that maximum polyphenols extraction could be obtained when the ethanol concentration and sonication time were $61 \%$ and 47 min respectively. It was worth noting that application of ultrasound energy for longer time decreased the extraction yield of polyphenols, which was probably due to polyphenol degradation. This is also in accordance with the reports of other researchers who have evaluated the effect of sonication time on polyphenols from spruce wood bark (Ghitescu et al., 2015) and arecanut (Chavan \& Singhal. 2013). However, the polyphenols yield decreased when the ethanol concentration was above $61 \%$, which suggested that an appropriate combination of alcohol with water was more effective in extracting phenolic compounds. The findings obtained from our study are in good agreement with Muñiz-Márquez et al. (2013).

\subsection{Optimization of extraction conditions and verification of model}

The model predicted a maximum yield of $44.74 \mathrm{mg} \mathrm{GAE} / \mathrm{g}$ DP at the optimum conditions, which involved an extraction temperature of $59^{\circ} \mathrm{C}$, a sonication time of $47 \mathrm{~min}$ and an ethanol concentration of $61 \%$ respectively.

Table 3. Analysis of variance (ANOVA) for the investigated systems.

\begin{tabular}{|c|c|c|c|c|c|}
\hline Source & Sum of Squares & DF & Mean Square & $F$-Value & $p$-Value \\
\hline Model & 908.57 & 9 & 100.95 & 29.02 & $<0.0001$ \\
\hline $\mathrm{X}_{1}$ & 642.61 & 1 & 642.61 & 184.72 & $<0.0001$ \\
\hline $\mathrm{X}_{2}$ & 20.61 & 1 & 20.61 & 5.92 & 0.0452 \\
\hline $\mathrm{X}_{3}$ & 1.90 & 1 & 1.90 & 0.55 & 0.4838 \\
\hline $\mathrm{X}_{1} \mathrm{X}_{2}$ & 2.74 & 1 & 2.74 & 0.79 & 0.4044 \\
\hline $\mathrm{X}_{1} \mathrm{X}_{3}$ & 0.13 & 1 & 0.13 & 0.038 & 0.8504 \\
\hline $\mathrm{X}_{2} \mathrm{X}_{3}$ & 2.06 & 1 & 2.06 & 0.59 & 0.4668 \\
\hline $\mathrm{X}_{1}^{2}$ & 99.46 & 1 & 99.46 & 28.59 & 0.0011 \\
\hline $\mathrm{X} 2^{2}$ & 63.89 & 1 & 63.89 & 18.36 & 0.0036 \\
\hline $\mathrm{X}_{3}{ }^{2}$ & 50.71 & 1 & 50.71 & 14.58 & 0.0066 \\
\hline Residual & 24.35 & 7 & 3.48 & & \\
\hline Lack of Fit & 14.57 & 3 & 4.86 & 1.98 & 0.2585 \\
\hline Pure Error & 9.79 & 4 & 2.45 & & \\
\hline Corrected Total & 932.92 & 16 & & & \\
\hline
\end{tabular}

$\mathrm{X}_{1}$ : Extraction temperature; $\mathrm{X}_{2}$ : Sonication time; $\mathrm{X}_{3}$ : Ethanol concentration; DF: degrees of freedom. 

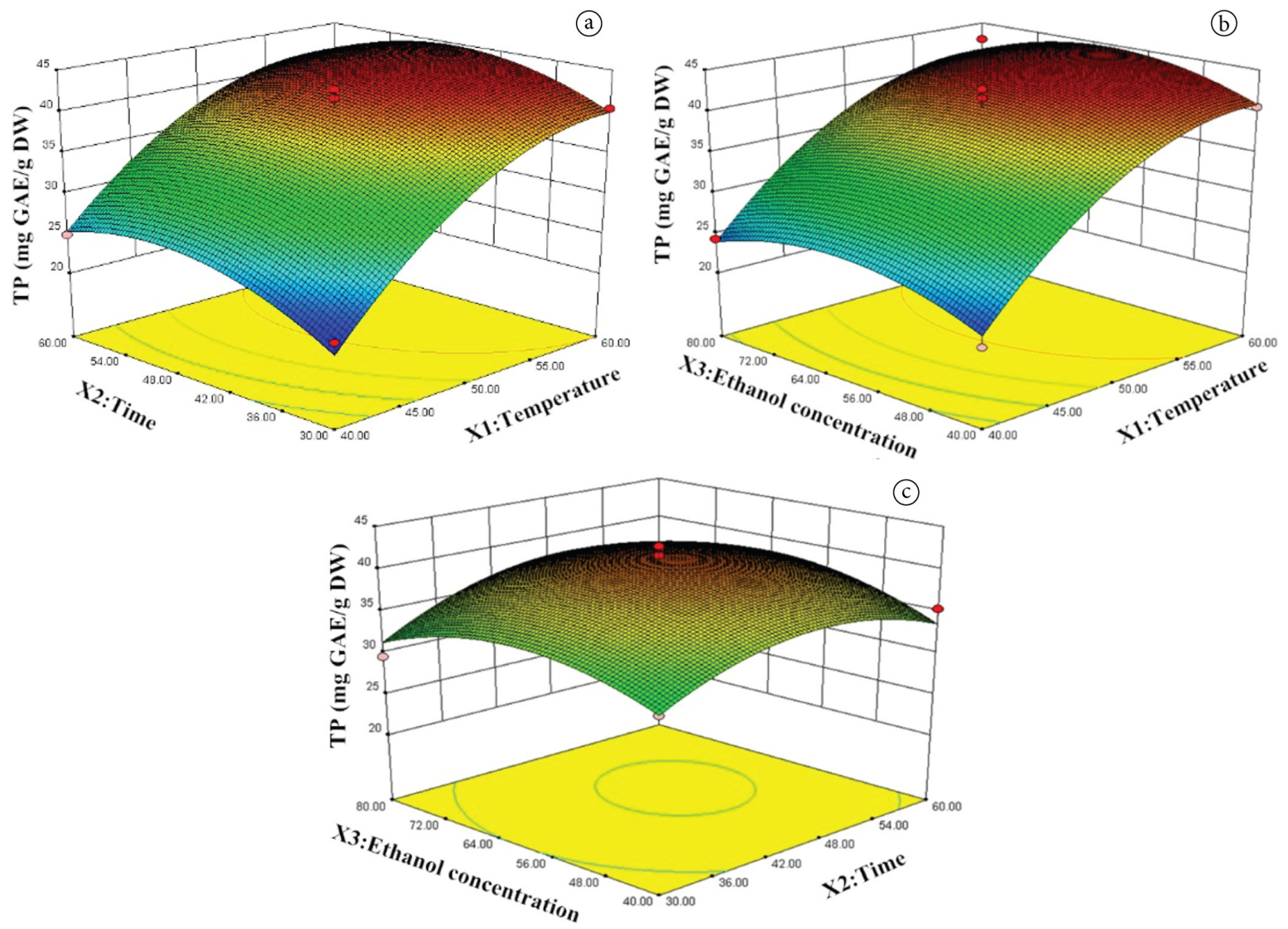

Figure 1. Response surface plots for polyphenols of the extracts as a function of (a) extraction temperature to sonication time (ethanol concentration $=60 \%$ ); (b) extraction temperature to ethanol concentration (sonication time $=45 \mathrm{~min}$ ); (c) sonication time to ethanol concentration (extraction temperature $=50^{\circ} \mathrm{C}$ ).

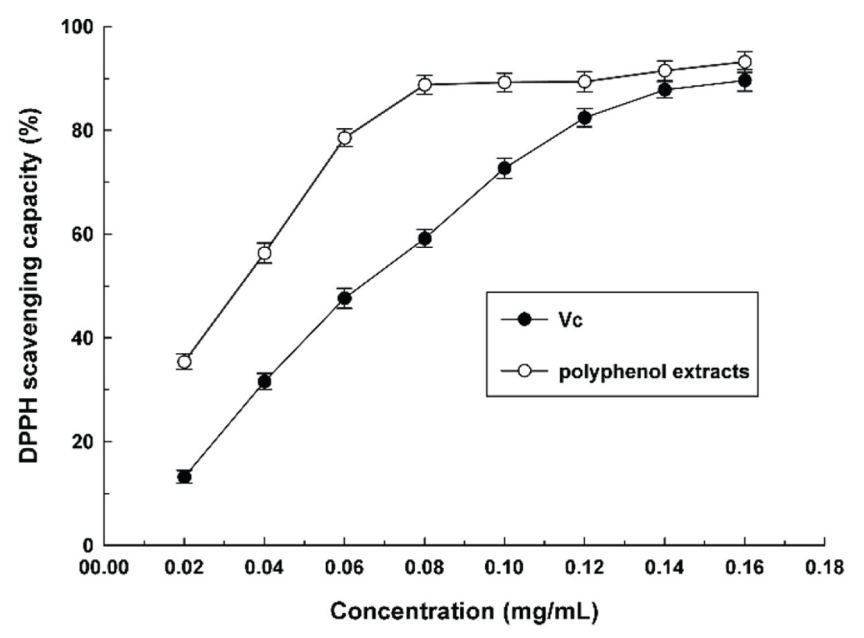

Figure 2. DPPH scavenging capacity of the polyphenol extracts from P. salicina.

Under the optimal conditions for three parallel experiments, polyphenols extraction yield was $43.85 \pm 0.74 \mathrm{mg} \mathrm{GAE} / \mathrm{g}$ DP, which amounted to $98.01 \%$ of theoretical prediction. This result indicates that the optimized model appropriately explains the actual extraction process of phenolic compounds.

\subsection{DPPH free radical scavenging capacity of polyphenol extracts from $P$. salicina}

DPPH radical scavenging assay was a widely used method to evaluate free radical scavenging activities of antioxidants. A dose-response curve of DPPH radicals scavenging capacities of the polyphenol extracts from P. salicina was presented in Figure 2. It was indicated that the DPPH radical-scavenging activity increased as the concentration of the extract increased. The polyphenol extracts from $P$. salicina showed higher activities than Vc in the concentration range of $0.02-0.16 \mathrm{mg} / \mathrm{mL}$. Meanwhile, $\mathrm{IC}_{50}$ values of polyphenol extracts $\left(\mathrm{IC}_{50}=0.034 \mathrm{mg} / \mathrm{mL}\right)$ was significantly lower than $\mathrm{Vc}_{\mathrm{c}}\left(\mathrm{IC}_{50}=0.065 \mathrm{mg} / \mathrm{mL}\right)$. The experimental results showed that the polyphenol extracts of the plums had a strong scavenging ability on DPPH radical.

\subsection{Hydroxyl radical scavenging activity of polyphenol extracts from P. salicina}

Hydroxyl radical is one of the potent reactive oxygen species in the biological system. It could cause severe damage to cell and lead to ageing, cancer and several other diseases (Yang et al., 2014). The scavenging activities of polyphenol extracts from $P$. salicina and $\mathrm{Vc}$ of various concentrations on hydroxyl radical are given in Figure 3. The hydroxyl radical scavenging ability of the two test samples increased with the increase of the concentration. 


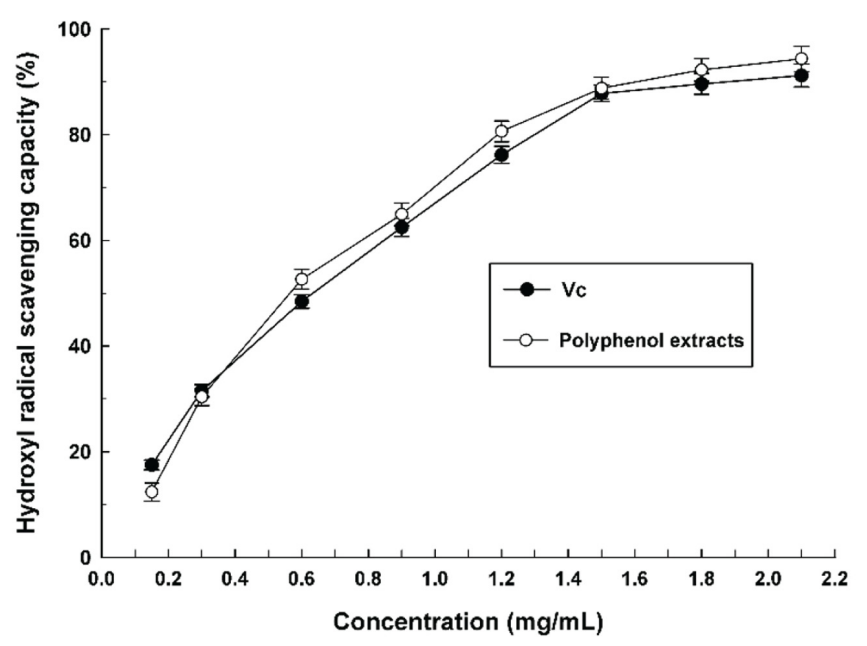

Figure 3. Hydroxyl radical scavenging capacity of the polyphenol extracts from $P$. salicina.

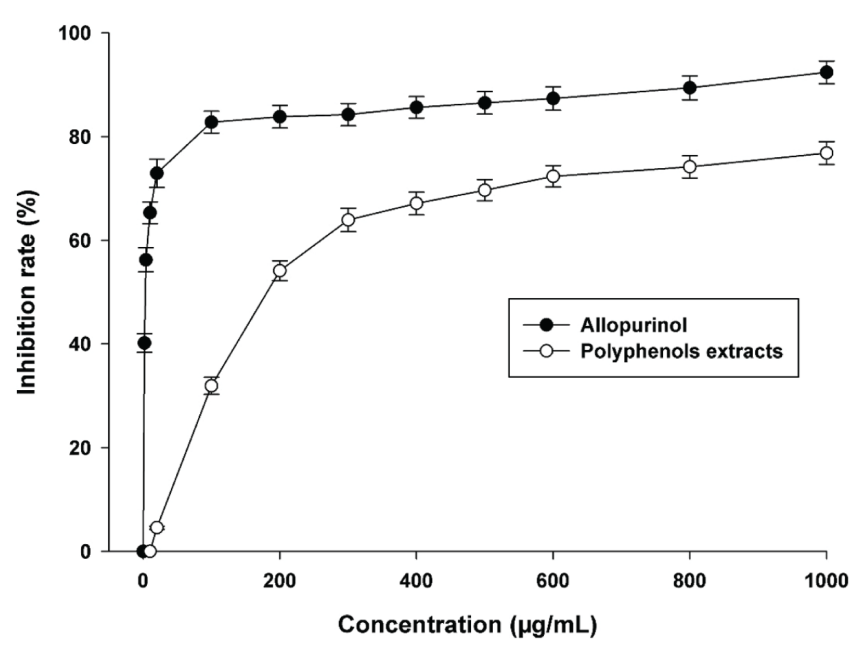

Figure 4. The inhibitory activity of polyphenols extracts from P. salicina on xanthine oxidase.

The $\mathrm{IC}_{50}$ values of polyphenol extracts from $P$. salicin and $\mathrm{Vc}$ were $0.56 \mathrm{mg} / \mathrm{mL}$ and $0.63 \mathrm{mg} / \mathrm{mL}$, respectively. These results suggested that polyphenol extracts from $P$. salicin was better natural antioxidant than $\mathrm{Vc}$ in scavenging hydroxyl radical.

\subsection{Xanthine oxidase inhibitory activity of polyphenol extracts from $P$. salicina}

Many metabolic disorders like gout and hyperuricemia are caused by elevated uric acid levels in blood, and xanthine oxidase $(\mathrm{XO})$ is responsible for uric acid production by converting hypoxanthine into xanthine, and xanthine in turn into uric acid (Neha \& Sanjai, 2014). Hence XO inhibitors, such as allopurinol, are usedwidely in the therapeutic approach for the treatment of gout and hyperuricemia (Hashim et al., 2013). However, allopurinol, as a widely used $\mathrm{XO}$ inhibitory agent, has various side effects such as renal toxicity and hypersensitivity reactions (Umamaheswari et al., 2009).
The xanthine oxidase inhibitory activities of polyphenols extracts from P. salicin and allopurinol were shown in Figure 4. With the increase of concentration, the inhibitory abilities of polyphenols extracts and Allopurinol on xanthine oxidase increased. As positive control, allopurinol showed a high inhibitory activity to xanthine oxidase at a low concentration. Polyphenol extracts from $P$. salicin also showed obvious inhibition of xanthine oxidase, which ranged from 0 to $63.94 \%$ at the concentration from 0 to $300 \mu \mathrm{g} / \mathrm{mL}$. The $\mathrm{IC}_{50}$ of polyphenol extracts from P. salicin and allopurinol was $179 \mu \mathrm{g} / \mathrm{mL}$ and $3.12 \mu \mathrm{g} / \mathrm{mL}$ respectively. These results indicate that polyphenol extracts from plums can be explored as a promising xanthine oxidase inhibitor.

\section{Conclusions}

The extraction conditions of polyphenols from Prunus salicina Lindl. were optimized by a Box-Behnken experiment design of three variables and three levels. Through the response surface method optimization, the optimal extraction conditions for the extraction of polyphenols were an extraction temperature of $59^{\circ} \mathrm{C}$, a sonication time of $47 \mathrm{~min}$, and an ethanol concentration of $61 \%$. Furthermore, the antioxidant activities of polyphenol extracts were evaluated by DPPH and hydroxyl radical scavenging assay. It exhibited stronger antioxidant activity compared to Vc. Polyphenol extracts showed significant inhibitory effect on xanthine oxidase, and the $\mathrm{IC}_{50}$ was $179 \mu \mathrm{g} / \mathrm{mL}$. Thus, Prunus salicina Lindl can be developed natural antioxidant and xanthine oxidase inhibitor agent in functional food or drug candidate. However, purification of polyphenol extracts and in vivo evaluation should be further studied.

\section{Acknowledgements}

The authors gratefully thanks the financial support of this study by the public service sectors (agriculture) project of China Agricultural Ministry (201503142) and the special fund of Fujian non-profit research institutes (2014R1015-3). At the same time, thank you for the support of Fujian Key Laboratory of Agricultural Product (Food) Processing.

\section{References}

Chavan, Y., \& Singhal, R. S. (2013). Ultrasound-assisted extraction (UAE) of bioactives from arecanut (Areca catechu L.) and optimization study using response surface methodology. Innovative Food Science \& Emerging Technologies, 17, 106-113. http://dx.doi.org/10.1016/j. ifset.2012.10.001.

Food and Agricultural Organization of the United Nations - FAO. (2016). Faostat. Rome: FAO. Retrieved from http://faostat.fao.org/ DesktopDefault.aspx?PageID=567\#ancor

Fu, L., Xu, B. T., Xu, X. R., Gan, R. Y., Zhang, Y., Xia, E. Q., \& Li, H. B. (2011). Antioxidant capacities and total phenolic contents of 62 fruits. Food Chemistry, 129(2), 345-350. http://dx.doi.org/10.1016/j. foodchem.2011.04.079.

Ghitescu, R. E., Volf, I., Carausu, C., Bühlmann, A. M., Gilca, I. A., \& Popa, V. I. (2015). Optimization of ultrasound-assisted extraction of polyphenols from spruce wood bark. Ultrasonics Sonochemistry, 22, 535-541. http://dx.doi.org/10.1016/j.ultsonch.2014.07.013. PMid:25132494. 
Hashim, N. H. N., Abas, F., \& Lajis, K. S. N. H. (2013). Antioxidant and xanthine oxidase inhibitory activities of persicaria hydropiper. International Journal of Food Properties, 16(5), 1028-1036. http:// dx.doi.org/10.1080/10942912.2011.575497.

Muñiz-Márquez, D. B., Martínez-Ávila, G. C., Wong-Paz, J. E., BelmaresCerda, R., \& Raúl Rodríguez-Herrera, C. N. (2013). Ultrasound-assisted extraction of phenolic compounds from Laurus nobilis L. and their antioxidant activity. Ultrasonics Sonochemistry, 20(5), 1149-1154. http://dx.doi.org/10.1016/j.ultsonch.2013.02.008. PMid:23523026.

Neha, K., \& Sanjai, S. (2014). Potential xanthine oxidase inhibitory activity of endophytic lasiodiplodia pseudotheobromae. Applied Biochemistry and Biotechnology, 173(6), 1360-1374. http://dx.doi. org/10.1007/s12010-014-0927-x. PMid:24801403.

Orsolya, O. G., Ildikó, L., Judit, H., Gusztáv, J., \& Andrea, V. (2015). Xanthine oxidase inhibitory activity of extracts prepared from polygonaceae species. Phytotherapy Research, 29(3), 459-465. http:// dx.doi.org/10.1002/ptr.5275. PMid:25510560.

Pérez-Jiménez, J., Neveu, V., Vos, F., \& Scalbert, A. (2010). Systematic analysis of the content of 502 polyphenols in 452 foods and beverages: an application of the phenol-explorer database. Journal of Agricultural and Food Chemistry, 58(8), 4959-4969. http://dx.doi.org/10.1021/ jf100128b. PMid:20302342.

Ramić, M., Vidović, S., Zeković, Z., Vladić, J., Cvejin, A., \& Pavlić, B. (2015). Modeling and optimization of ultrasound-assisted extraction of polyphenolic compounds from Aronia melanocarpa by-products from filter-tea factory. Ultrasonics Sonochemistry, 23, 360-368. http://dx.doi.org/10.1016/j.ultsonch.2014.10.002. PMid:25454824.

Scalbert, A., Manach, C., Morand, C., Rémésy, C., \& Jiménez, L. (2005). Dietary polyphenols and the prevention of diseases. Critical
Reviews in Food Science and Nutrition, 45(4), 287-306. http://dx.doi. org/10.1080/1040869059096. PMid:16047496.

Sun, Y. X., \& Kennedy, J. F. (2010). Antioxidant activities of different polysaccharide conjugates (CRPs) isolated from the fruiting bodies of Chroogomphis rutilus (Schaeff.: Fr.) O. K. Miller. Carbohydrate Polymers, 82(2), 510-514. http://dx.doi.org/10.1016/j.carbpol.2010.05.010.

Umamaheswari, M., Asokkumar, K., Sivashanmugam, A. T., Subhadradevi, V., \& Ravi, T. K. (2009). In vitro xanthine oxidase inhibitory activity of the fractions of Erythrina stricta Roxb. Journal of Ethnopharmacology, 124(3), 646-648. http://dx.doi.org/10.1016/j. jep.2009.05.018. PMid:19467311.

Vallverdú-Queralt, A., Regueiro, J., Alvarenga, J. F. R., Martinez-Huelamo, M., Leal, L., \& Lamuela-Raventos, R. M. (2015). Characterization of the phenolic and antioxidant profiles of selected culinary herbs and spices: caraway, turmeric, dill, marjoram and nutmeg. Food Science and Technology, 35(1), 189-195. http://dx.doi.org/10.1590/1678457X.6580.

Wood, J. E., Senthilmohan, S. T., \& Peskin, A. V. (2002). Antioxidant activity of procyanidin-containing plant extracts at different $\mathrm{pHs}$. Food Chemistry, 77(2), 155-161. http://dx.doi.org/10.1016/S03088146(01)00329-6.

Yang, X., Yan, F., Huang, S., \& Fu, C. (2014). Antioxidant activities of fractions from longan pericarps. Food Science and Technology, 34(2), 341-345. http://dx.doi.org/10.1590/S0101-20612014005000034.

Yu, J., Wang, L., Walzem, R. L., Miller, E. G., Pike, L. M., \& Patil, B. S. (2005). Antioxidant activity of citrus limonoids, flavonoids, and coumarins. Journal of Agricultural and Food Chemistry, 53(6), 2009-2014. http://dx.doi.org/10.1021/jf0484632. PMid:15769128. 